\title{
Postmodern Mathematics
}

\author{
Paul Ernest
}

\section{Aim and Rationale}

The goal was to elucidate the nature of postmodern mathematics and mathematics education, including the multiplicity of the subject of mathematics; and to explore and share ideas of how postmodern perspectives offer new ways of seeing mathematics, teachers, learners, mathematics education theories, research and practice. The two key themes originally used to organizer the sessions are as follows.

Theme 1 What does postmodern mathematics mean? Part of this means exploring perspectives of mathematics as a plurality, as having multiple forms, identities, locations. Even the name mathematics is plural, although modern(ist) usage overlooks this anomaly in treating it/them as a single entity.

Theme 2 What does postmodern mathematics education mean? This involves considering multiple-self perspectives of the human subject as teacher, learner or researcher.

Organizers Co-chairs: Paul Ernest (UK), Regina Möller (Germany); Team Members: Ubiratan D’Ambrosio (Brazil), Allan Tarp (Denmark), Sencer Corlu (USA), Gelsa Knijnik (Brazil), Maria Nikolakaki (Greece); Liaison IPC Member: Michèle Artigue (France).

P. Ernest ( ()

University of Exeter, Exeter, UK

e-mail: p.ernest@ex.ac.uk 


\section{Background}

Postmodernism rejects a single authoritative way of seeing mathematics, teachers and learners, for each can be seen and interpreted in multiple ways. Mathematics can be seen as axiomatic and logical leading to indubitable conclusions, but it can also be seen as intuitive and playful, open-ended, with surprises and humour, as evidenced in popular mathematical images and cartoons. Additionally it can be seen in its applications in science, information and communication technologies, as well as in everyday life and ethnomathematics. All of these dimensions are part of what makes up mathematics and they all co-exist successfully.

This perspective asserts that there is no such thing as mathematics. There is no unique object named by the term. There is no unique or fixed identity for the various knowledge realms, activities, practices, forms, identities or locations connoted by the term. However, mathematics (in the plural) do exist-evidently there is a multiplicity connoted by this term that varies according to the times, places, and purposes for which they are invoked. These different mathematics bear what Wittgenstein terms a family resemblance. There is no essential defining character shared by them all, but to a greater or lesser extent, they are recognizably related.

It is also important to recognize that all human subjects have multiple selves and that we all (mathematicians, teachers and learners - and we are always all three) have access to different selves: authoritative knowers, researchers, learners, appreciators and consumers of popular and other cultures, as well as having nonacademic selves. Thus mathematics teachers can be seen as epistemological authorities in the classroom as well as co-explorers of unfamiliar realms both mathematical and cultural; and as ring-masters in the mathematical circus. Students can be seen as receivers of mathematical knowledge, but also as explorers, interpreters and sometimes even creators of mathematics and cultural realms that can be related to mathematics. All of these perspectives and selves are resources we can use to enhance the teaching and learning of mathematics, but many are currently overlooked or excluded.

Discussion Group aimed to provoke discussion on these and other issues, to raise and discuss these ideas and explore and generate examples relevant to classroom practices.

Papers, resources and discussions were shared on-line before the conference both via the official ICME-12 site and via Allan Tarp's MATHeCADEMY.net website. The purpose was to begin discussions before the conference and to share planned presentations in advance so that participants could prepare themselves and presentations could be kept short and much of the group time devoted to discussion and contributions from participants. As judged by informal feedback, the discussion group was very successful in this respect. 


\section{Key Questions}

- Is there such a thing as postmodern mathematics?

- What is postmodern thinking in mathematics and mathematics education? What is new or different about it and what are the implications for research in mathematics education?

- Given a postmodern multiple-perspectives view of mathematics what illuminations and surprises can be found for mathematics and its teaching and learning in multidisciplinary sources including: history of mathematics, ethnomathematics, science, information and communication technology, art works, stories, cartoons, films, jokes, songs, puzzles, etc.?

- How might the new emphases and differences foregrounded by postmodern perspectives impact in the primary and secondary mathematics classrooms? What concrete examples serve to illustrate these differences?

- How can a multiple-selves view of the human subject be reflected in the mathematics classroom and in mathematics teacher education? How can a multiple-selves view of the teacher facilitate teacher education?

- To what extent are the theories and presentations offered at the conference and elsewhere in publications actually post-modern?

The discussion group opened with the showing of an animated movie discussion on Postmodern Mathematics Education between avatars for Paul Ernest and Allan Tarp. The movie is accessible at: http://www.youtube.com/watch? $=$ ArKY2y_ve_U and the script for the animated movie has been published in The Philosophy of Mathematics Education Journal no. 27, retrievable via http://people.exeter.ac.uk/ PErnest/.

Among the key distinctions made in this dialogue were those between philosophical and cultural postmodernism. The former is concerned with multiple epistemologies and representations of knowledge, whereas the latter is more frivolous concerning the eclectic conjoining of different styles, with pastiche, bricolage and irony. The second distinction is between Anglo postmodernism (e.g., Rorty) with its focus on knowledge and uncertainty, and continental postmodernism with its emphasis on power (e.g., Foucault).

The remaining presentations in the group were as follows:

- Bill Atweh, Is the Good a Desire or an Obligation? The Possibility of Ethics for Mathematics Education

- Bal Chandra Luitel and Peter Charles Taylor, Fractals of 'Old' and 'New' Logics: A Post/modern Proposal for Transformative Mathematics Pedagogy

- Peter Collignon and Regina D. Möller, Postmodern Analysis

- Regina D. Möller and Elisabeth Mantel, Postmodern approaches in teacher education

- Allan Tarp, Postmodern Mathematics Education in Practice

- Paul Ernest, The importance of being erroneous in maths: to be wrong or not to be wrong? 
Two further papers accepted for the group have been shared online as the presenters were unavoidably detained at the last minute and unable to present in person:

- Mônica Mesquita and Sal Restivo All Human Beings as Mathematical Workers: Sociology of Mathematics as a Voice in Support of the Ethnomathematics Posture and Against Essentialism

- Ilhan M. Izmirli Wittgenstein as a Social Constructivist

An invitation was given to all presenters and participants to comment or publish papers in The Philosophy of Mathematics Education Journal. Papers 1, 2, 7 and 8 have been published in The Philosophy of Mathematics Education Journal no. 27 (2013), retrievable via http://people.exeter.ac.uk/PErnest/.

The meetings were well attended and there was a lively and controversial set of presentations, questions and responses including extensive audience generated questioning and dialogue. The most frequent question directed to speakers was: "The presentation was interesting, but it could also be given under a cognitivist or constructivist framework! In what way was it postmodern?"

Several presenters answered this from their own perspectives. Paul Ernest's answer is that the social constructivism he has been developing is intended to be a postmodern philosophy of mathematics and mathematics education because:

- It rejects absolutism and accepts multiple perspectives on mathematics and teaching and learning;

- It is grounded in human practices (language games embedded in forms of lifefollowing Wittgenstein) - and this pre-knowable grounding and reality takes precedence over any theorizing (and also installs a deep ethics as the first philosophy of mathematics education);

- It refuses priority to either A the objective or subjective forms of knowledge, B the social or individual forms of being, or $\mathrm{C}$ the structural or agentic forms of power-arguing that these are mutually constitutive pairs - two sides of the same coin.

All participants were delighted to be involved with a controversial contemporary topic that is genuinely best approached through discussion.

Open Access This chapter is distributed under the terms of the Creative Commons Attribution Noncommercial License, which permits any noncommercial use, distribution, and reproduction in any medium, provided the original author(s) and source are credited. 